\title{
Relationship between Parenting Style and Children's Behavior Problems
}

\author{
Shahla Alizadeh \\ Department of Human Development \& Family Studies \\ Faculty of Human Ecology, University of Putra Malaysia (UPM), Malaysia \\ E-mail: alizadeh_shahla@yahoo.com \\ Dr. Mansor B Abu Talib \\ Department of Human Development \& Family Studies \\ Faculty of Human Ecology, University of Putra Malaysia (UPM), Malaysia \\ E-mail: mansorat@gmail.com \\ Dr. Rohani Abdullah \\ Department of Human Development \& Family Studies \\ Faculty of Human Ecology, University of Putra Malaysia (UPM), Malaysia \\ E-mail: rohani_safri@yahoo.com \\ Dr. Mariani Mansor \\ Department of Human Development \& Family Studies \\ Faculty of Human Ecology, University of Putra Malaysia (UPM), Malaysia \\ E-mail: mariani@putra.upm.edu.my
}

Received: June 20, 2011

doi:10.5539/ass.v7n12p195
Accepted: August 3, $2011 \quad$ Published: December 1, 2011

URL: http://dx.doi.org/10.5539/ass.v7n12p195

\begin{abstract}
In the family, parenting style directly impacts children's behavior and symptoms of behavior. There is ample evidence to support the correlation between parenting style and children's behavioral problems. However, parenting style and children's behavioral problems have received little attention and research interest in Iran. Therefore, the current research is deemed necessary and timely. Thus, the major purpose of this current study is to investigate the relationship between parenting style and children's behavioral problems. Parenting styles (Authoritative, Permissive, and Authoritarian) were assessed by Parent Authority Questioner (PAQ) and children's behavioral problems (internalizing and externalizing symptoms) were assessed with the Children's Behavior Checklist (CBCL). Respondents comprised 681 mothers of children in primary school (347girls and 334 boys) who were identified through their children selected by cluster sampling in the Iranian capital of Tehran. The results of the present study indicate that there is a significant correlation between Authoritative and internalizing $(\mathrm{r}=-.32, \mathrm{p}<.001)$ externalizing $(\mathrm{r}=-.28, \mathrm{p}<.001)$, Permissive and internalizing $(\mathrm{r}=.12, \mathrm{p}<.001)$, externalizing $(\mathrm{r}=.12, \mathrm{p}<.001)$, Authoritarian and internalizing $(\mathrm{r}=.25, \mathrm{p}<.001)$, externalizing $(\mathrm{r}=.26, \mathrm{p}<.001)$. In conclusion Authoritative parenting style with high responsiveness and high demanding in parenting behavior has shown to be directly related to less children's internalizing and externalizing symptoms.
\end{abstract}

Keywords: Parenting style, Children's behavioral problems, Internalizing, Externalizing 


\section{Introduction}

In the past two decades children's behavioral problems, including externalizing and internalizing have received considerable attention from researchers (Cartwright, Hatton, 2005). Since 1991, Achenbach and his students have conducted many studies using the Children's Behavioral Check List (CBCL) as the instrument to identity children's behavioral problems. The problems related to depression, anxiety, withdrawal and physical complaints are recognized as internalization problems, whereas problems like violence, rebelliousness, disobedience and drug use are categorized as externalization ones (Phares, 2003).

The family is a socio-cultural-economic arrangement that exerts significant influence on children's behavior and the development of their characters (Baumrind, 1991). Any ignorance on the part of parents may lead to unwanted damaging effects on children's growth and thereafter may create misbehavior problems in children. Parenting is a composite activity that is the sum of many particular behaviors working together or individually, to finally have an effect on the child's behavior (Baumrind 1978). Specific parenting behaviors, such as physical punishments, may affect children's development and consequently cause behavioral disorders in them. The pattern of parenting style is utilized to get normal variations in parents' endeavor in order to control and socialize their children (Baumrind, 1991). Parenting, according to Baumrind (1967) categorized parents based on two dimensions, responsiveness and demanding. The responsiveness and demanding create three different kinds of parenting styles: Authoritative style has a high responsiveness and high demanding. Authoritarian style has low responsiveness and high demanding, and finally, Permissive style, which is labeled by high responsiveness and low demanding. In Authoritative style high responsiveness and high demanding in parenting behavior has been shown to be directly related to less children's misbehavior and symptoms. (Baumrind, 1991). According to the Baumrind parenting style model theory, it is assumed that different kinds of parenting style lead to children's misbehavior.

According to the above, parenting style has a relationship with children's behavioral problems. Although much work has been done about this variable, there are not enough studies carried out to date linking children's behavioral problems with parenting style in Iran. Thus, more studies are needed to understand the relationship between parenting practice and children's misbehavior. The focus of the present study is the relationship between the above mentioned variables.

\section{Previous Research}

Baumrind, in 1991, reported that parents who are authoritative were more successful than authoritarian parents, especially in helping their adolescents to avoid problems associated with drugs. Also, consistent utilization of external reinforcements and too much focus on conformity to authority decrease adolescents' awareness of competence, self-sufficiency, and inner enthusiasm to achieve. Fletcher, Walls, Cook, Madison, \& Bridges (2008) however reported that a mother's authoritative parenting style had a negative relation with internalizing symptoms. Furthermore, Harper (2010) reported that increased authoritative fathering is associated with increased internalizing problems. Williams et al. (2009) claimed that high authoritative parenting was associated with fewer tendencies in internalizing symptoms of children. On the other hand, Wu (2009) demonstrated that mother's permissive parenting style is associated with anti-social behavior among their children. Moreover, Sommer (2007) reported that permissive parenting style is positively associated with a child's externalizing behavioral problems. Also, Brar (2003) documented that authoritarian parenting style has a significant correlation with externalizing behavioral problems. Furthermore, Odubote (2008) reported that authoritarian parenting style is highly correlated with delinquency behavior, adding that the authoritative parenting style has been associated with positive outcomes. In contrast permissive and authoritarian parenting style has been associated with delinquency. Also Palmer (2009) found that authoritative parenting was positively correlated with children's adjustment, and authoritarian parenting was negatively correlated with children's adjustment. In addition, it was reported that parental self-control skills were positively correlated with authoritative parenting. In another research carried out by Darling, McCartney, \& Taylor (2006), a significant relationship was found between parenting styles and depression. This study indicated that children of Authoritarian parents have more depression compared to children of the uninvolved ones. Pellerin (2005) in a study applied Baumrind's authoritative, authoritarian, and permissive parenting to high schools as socializing negotiators. The findings of this study showed that school styles produced the same results as parenting styles. Consequently, the authoritative schools demonstrated the best outcomes and indifferent schools showed the worst results for disentanglement, whereas authoritarian schools have the worst outcomes for dropout. 


\section{Objective}

The main objective of this present study is to determine the relationship between maternal parenting styles (Authoritative, Authoritarian, Permissive) and children's behavioral problems (internalizing and externalizing symptoms) amongst Iranian mothers and children in Tehran.

\section{Methodology}

\subsection{Sample and procedure}

The population for this study was mothers in Tehran with children studying in elementary school. The sample in this study consisted of 681 mothers of students in elementary school (levels 3, 4, 5), who were chosen from eight schools In Tehran. Mothers were identified through their children who comprised 347 girls from four schools and 334 boys from four schools chosen by cluster random sampling. Initially, permission from the $19^{\text {th }}$ region of the Iranian Ministry of Education in Tehran was sought.

\subsection{Measures}

Children's Behavioral Checklist (CBCL) Questionnaire: This includes forms to evaluate competency, and affective-behavioral problems. The CBCL is an instrument from Achenbach System of Empirically Based Assessment (ASEBA). This instrument arranges two broad-band behavior problems, internalizing and externalizing symptoms based on total T scores. Children with a CBCL T score of 63 or above for either of the internalizing or externalizing behaviors or both, were considered at clinical risk. The parent responds using a 3 -point Likert scale. Each item is scored by a quantitative scale like; $(0)=$ not true of the child, (1) =sometimes true, (2) =often true. The CBCL form, which is filled out by the parents, has a reliability of $93 \%$, whose reliability for affective and behavioral symptoms is $90 \%$. The internal stability of the scale with an alpha of 0.63 is $79 \%$ in CBCL. After cultural, social and lingual adjustments, this index, through a multi-stage sampling method, a population of 1438 students, including 698 girls and 749 boys, and according to educational level from three districts of Tehran including north, center and south and also from the attendance of the psychology section of Rouzbeh Hospital was chosen. Then, the different forms of this system were held (given to be filled out). The internal similarity of the relevant scale was $70 \%$ and the scales of the second part were satisfying. In the validity of test-post-test, all the correlations were significant for Pearson's moment production. For the structural reliability, first, internal reliability of the scales was investigated, which was all significant and then to distinguish between the clinical group and the normal one, the independent groups were evaluated with a t-test (Minaei, 2006). The CBCL contained eight sub-scales for internalizing and externalizing problems: Anxious/Depressed (14 items), Somatic complaints (9 items), Withdrawn (9 items), thought problem (7 items), Aggressive behavior (20 items), Attention and hyperactivity problems (11 items), Delinquent behavior (13 items), and Social problems (8 items), and other problems (33items). In addition a total problem score will be measured. (Achenbach \& Rescorla, 2001).

Parent Authority Questionnaire (PAQ) developed by Buri (1991) was designed to measure Baumrind's three dimensions: Authoritative, Authoritarian, and Permissive. The PAQ has internal consistency with alpha from .74 to .87 for subscales the stability of this questionnaire with two weeks test-retest reliabilities from .77 to .92 . This questionnaire was investigated by Esfandiari (1995) to determine its validity and reliability. In this intercultural research test-retest reliability of the permissive was .69 and for the authoritarian was .78 while it was .73 for the authoritative. The parent responds using a 5-point Likert scale. Each item is scored by a quantitative scale like: strongly disagree $=(1)$, disagree $=(2)$, neither agree nor disagree $(3)$, agree $=(4)$, strongly agree $=(5)$

\section{Results}

The results indicate that there is a significant correlation between the parenting style of mothers and children's behavioral problems. The mean and standard deviations for Authoritative level of mothers were $\mathrm{M}=38.23$, $\mathrm{SD}=6.38$, for Permissive level of mothers $(\mathrm{M}=29.84, \mathrm{SD}=5.48)$, for Authoritarian level of mothers $(\mathrm{M}=30.28$, $\mathrm{SD}=6.27)$. The mean and standard deviations for internalizing symptoms were $(\mathrm{M}=11.83, \mathrm{SD}=8.04)$, and for externalizing symptoms were $(\mathrm{M}=10.21, \mathrm{SD}=8.08)$. The Authoritative level of mothers had negatively significant correlation with internalizing symptoms in children. Therefore, high Authoritative level of mothers had negative relation with low level of internalizing symptoms $[\mathrm{r}=-.32, \mathrm{n}=681, \mathrm{p}<.01]$. On the other hand, the Authoritative level of mothers was negatively significant in externalizing symptoms in children. Therefore, higher authoritative level will lead to lower level of externalizing $[\mathrm{r}=-.28, \mathrm{n}=681, \mathrm{p}<.01]$. The Permissive level of mothers has positive significant correlation with internalizing symptoms in children. The result shows that when mother's permissive level is high, their children have greater tendency towards internalizing behavior $[\mathrm{r}=.12, \mathrm{n}=681, \mathrm{p}<.01]$. Also, the Permissive level of mothers has a positive significant correlation with 
externalizing symptoms in children. This means that a high Permissive level has positive relationship with a high level of externalizing symptoms $[\mathrm{r}=.12, \mathrm{n}=681, \mathrm{p}<.01]$. Lastly, the Authoritarian level of mothers has significant correlation with internalizing and externalizing symptoms in children whereby high Authoritarian level leads to high level of internalizing symptoms $[\mathrm{r}=.25, \mathrm{n}=681, \mathrm{p}<.01]$ and a high level of externalizing symptoms $[\mathrm{r}=.26, \mathrm{n}=681, \mathrm{p}<.01]$.

\section{Discussion}

The findings of the present study highlight significant relationships between the parenting styles of mothers with children's behavioral problems. The present study carried out among Iranian mothers in the Iranian context supports the findings of various researches which have shown the relationship between parenting style and children's behavioral problems (Williams et al., 2009; Harper, 2010; Fletcher et al., 2008; Maccoby, 1992 \& Baumrind, 1991; Palmer, 2009; Brar, 2003; Wu, 2009; Sommer, 2007).

According to Baumrind, parenting style theory (Maccoby 1992; Baumrind 1991; 1978; 1969), authoritative parents have supporting style. They are mostly adopted by parents who had both responsive dimensions and demanding. If they had rational demand from their children; they would respond accordingly to the children's need. Authoritative parents also recognized what was their own special right and that of their children. When parents have certain expectations from their children and exhibit responsive and supportive behavior, the children can create their own self-confidence and responsibility with less problematic behaviors, high rate of social skills, greater creativity and better academic performance in school. In contrast, due to high response demand between parents and children, Baumrind $(1969 ; 1978 ; 1991)$ demonstrated that permissive parents responded but were not demanding, so these parents lacked the demanding dimension. Thus, permissive parents dislike control and authority over their children. They do not guide their children to regulate their behavior and allow them to make their decisions alone. Therefore, their children will receive passive and unresponsive character in their interaction with others. As a consequence, they become dependent and lack social responsibility and are low in cognitive development. It is assumed that the permissive parenting style will be associated positively with children's behavioral problems either internalizing or externalizing behaviors.

Reflecting on Baumrind's theory $(1991 ; 1978 ; 1969)$, authoritarian parents are not only demanding but they are unresponsive to the demand set by their children. Parental power is important thus, punishment, force and harshness are mostly techniques that authoritarian parents use to exhibit their authority. Nevertheless, corporal punishment in childhood may result in suicide, depression in adulthood or other problems that may manifest in later stages of the children's life. They are not warm and seem to use more punishment, and therefore the authoritarian parents adopting such practice can influence the behaviors of their children and their activities in society have been unsuccessful; and therefore, such a family will be subject to misbehavior and other psycho-social behavior (Gallimore and Kurdek 1992).

\section{Conclusion}

Findings from this study reveal that different parenting style is associated with low or high children's behavioral problems. Authoritative parenting style continues to influence children's development in positive ways beyond childhood and also adolescence. Conceptually, the authoritative style parents have both responsive and demanding dimensions. Their children have fewer behavioral problems and a high rate of academic achievement in school. Thus, with high demand and responsiveness between parent and child, there will be less internalizing and externalizing symptoms. In contrast, permissive parents are responsive but they are not demanding. So their children tend to get passive and be unresponsive in their interaction with others, become dependent and lack social responsibility. Therefore, it is assumed that the permissive parenting style will be associated positively with internalizing and externalizing behavior in children. Also, authoritarian parents are only demanding but they are unresponsive. They utilize the punishment for their own children. Hence, being too strict in childhood may result in children's behavior problems.

The present research however, has some limitations. Its findings are limited to children's behavioral problems with only maternal parenting style type. Future research should also investigate other variables such as parents' attachment, parent's stress, parent's empathy, etc, which are critical. The present research was also limited to parenting style factors on children's misbehavior. Regarding many relevant factors affecting children's problems such as age, genetics, socio-economics, peer pressure, parent's income, society, school, etc, we considered only parenting style type. It is recommended that future research should also consider other relevant factors affecting children's misbehavior as moderator such as; age, gender, peers...etc. This research was also limited to $3^{\text {rd }}, 4^{\text {th }}$, and $5^{\text {th }}$ levels of primary school. Therefore it is limited to a particular generation and excludes other age ranges and grades of education. 


\section{References}

Achenbach, T.M., \& McConaughy, S.H. (1996). Empirically based Assessment of Child and Adolescent Psychopathology. Practical application. Development clinical psychology and psychiatry, 13.

Achenbach, T.M., \& Rescorla, L.A. (2001). Manual for ASEBA school-age forms and profiles. Burlington, VT: University of Vermont, Research Center for Children, Youth, \& Families.

Baumrind, D. (1967). Child Care Practices Anteceding Three Patterns of Preschool Behavior. Genetic Psychology Monographs, 75: 43-88.

Baumrind, D. (1978). Parental disciplinary patterns and social competence in children. Youth and Society, 9. 239-276.

Baumrind, D. (1991). Effective parenting during the early adolescent transition. In P. A. Cowan \& E. M. Hetherington (Eds.) Family transitions. Advances in family research series. Hillsdale, NJ, England: Lawrence Erlbaum Associates, Inc.

Brar, Sh. (2003). Child temperament, parenting style and externalizing and internalizing behavior of young children of Indian immigrants in Canada. (Doctoral dissertation, University of Massachusetts). [Online] Available: http://proquest.umi.com

Buri, J. R. (1991). Parental Authority Questioner. Department of Psychology, University of St. Thomas, St. Paul, MN 55105, USA.

Cartwright-Hatton, S. McNally, D., White, C., \& Verduyn C. (2005). parent skill training: An effective intervention for internalizing symptom in younger children. Journal of child and adolescent Psychiatric Nursing, 7, 128-139.

Darling, E., McCartney, K., \& Taylor, B.A. (2006). Within-child associations between family income and externalizing and internalizing problems. Developmental Psychology, 42, 237-252. http://dx.doi.org/10.1037/0012-1649.42.2.237

Esfandiari, Gh. (1995). Comparison of parenting style of mothers with children behavioral disorders and mothers of normal children. (Unpublished Master of clinical psychology's thesis. Institute Psychiatry of Iran-Tehran).

Fletcher, A.C., Walls J.K., Cook, E. C., Madison, K. J., \& Bridges, T. H. (2008). Parenting style as a moderator of associations between Maternal disciplinary strategies and child well-being. Journal of family issues, 29, 12. http://dx.doi.org/10.1177/0192513X08322933

Harper, S. E. (2010). Exploring the role of Filipino fathers: parental behavior and child outcomes. Journal of family issues, 3 (1), 66-89. http://dx.doi.org/10.1177/0192513X09342858

Maccoby, E. E. (1992). Trends in the study of socialization: Is there a Lewinian heritage? Journal of Social Issues, 48, 171-185. http://dx.doi.org/10.1111/j.1540-4560.1992.tb00892.x

Minaei, A. (2006). The manual of CBSL test according of Achenbach experience (ASEBA). Research on Exceptional Children, 19, 1, 529-558.

Odubote, B.A. (2008). Parenting style, race and delinquency: A comparative study of European American, African American and Nigerian families. (Doctoral dissertation, University of Minnesota). [Online] Available: http://proquest.umi.com

Palmer, C. D. (2009). Parenting style and self control skills. (Doctoral dissertation. University of Hawaii). [Online] Available: http://proquest.umi.com

Pellerin, L. A. (2005). Applying Baumrind's Parenting Typology to High Schools: Towards a Middle-range Theory of Authoritative Socialization. Social Science Research, 34: 283-303. http://dx.doi.org/10.1016/j.ssresearch.2004.02.003

Phares, V. (2003). Understanding abnormal child psychology. USA: John Wiley \& Sons, Inc.

Sommer, K.L. (2007). The relationship between parenting style, parental reading involvement, child behavior outcomes, child classroom competence and early childhood literacy. (Master thesis, University of Oklahoma state). [Online] Available: http://proquest.umi.com

Williams, L. R., Degnan, K. A., Perez- Edgar, K. E., Henderson, H. A., Kenneth, R. H., Pine, D. S., Steinberg, L., \& Nathan, A.F. (2009). Impact of behavioral inhibition and parenting style on internalizing and externalizing 
problems from early childhood through adolescence. Journal of spring science and Business media, LLC. http://dx.doi.org/10.1007/s10802-009-9331-3

$\mathrm{Wu}, \mathrm{M}$. (2009). The relationship between parenting styles, career decision self-efficacy, and career maturity of Asian American college students. (Doctoral dissertation. University of Southern California). [Online] Available: http://proquest.umi.com

Table 1. Mean \& Std.Deviation \& frequency among of variables

\begin{tabular}{|c|c|c|c|c|}
\hline Variables & Mean & Std.Deviation & Frequency & $\%$ \\
\hline Authoritative & 38.23 & 6.38 & 463 & 68 \\
Permissive & 29.84 & 5.48 & 92 & 13.5 \\
Authoritarian & 30.15 & 6.27 & 126 & 18.5 \\
Internalizing & 11.83 & 8.04 & 295 & 43.78 \\
Externalizing & 10.21 & 8.08 & 229 & 33.62 \\
\hline
\end{tabular}

Table 2. Correlation among of variables

\begin{tabular}{llrrrrr}
\hline & Variables & 1 & 2 & 3 & 4 & 5 \\
\hline 1 & Authoritative style & & & & & \\
2 & Permissive style & $-.174(* *)$ & - & & & \\
3 & Authoritarian style & $-.229(* *)$ & $.082\left(^{*}\right)$ & - & \\
& & & & & & \\
4 & Internalizing symptom & $-.325(* *)$ & $.129(* *)$ & $.255(* *)$ & - & \\
& & & & & & \\
5 & Externalizing symptom & $-.286(* *)$ & $.127(* *)$ & $.267(* *)$ & $.650(* *)$ & - \\
\hline
\end{tabular}

